\title{
Prenatal screening of DiGeorge (22q11.2 deletion) syndrome by abnormalities of the great arteries among Thai pregnant women
}

\author{
Kuntharee Traisrisilp, MD, Fuanglada Tongprasert, MD, Kasemsri Srisupundit, MD, Suchaya Luewan, MD, \\ Theera Tongsong, MD \\ Department of Obstetrics and Gynecology, Faculty of Medicine, Chiang Mai University, Chiang Mai, Thailand
}

\section{Objective}

22q11.2DS (deletion syndrome) is one of the common serious anomalies resulting in high perinatal morbidity and mortality rate. Nevertheless, prenatal diagnosis of 22q11.2DS in Southeast Asia has never been described and its prevalence in prenatal series has never been explored. The objective of this study was to describe the experience of prenatal diagnosis of 22q11.2DS in the Thai population and to determine its prevalence among fetuses prenatally diagnosed with abnormalities of the great arteries.

\section{Methods}

A prospective study was conducted on pregnant Thai women prenatally diagnosed with abnormalities of the great arteries in the second trimester. The recruited cases were investigated for fetal 22q11.2 deletion by in situ hybridization with a probe specific to the DiGeorge/NCFS TUPLE 1 region located on chromosome 22 for the locus D22S75, and 22qter for a telomere specific sequence clone as the control region.

Results

Five out of the $42(11.9 \%)$ fetuses with abnormalities of the great arteries meeting the inclusion criteria were proven to have 22q11.2DS. The most common abnormalities were the tetralogy of Fallot (or variants) and right-sided aortic arch, followed by a thymic hypoplasia.

\section{Conclusion}

As observed in the western countries, we have documented that, among pregnant Thai women, 22q11.2DS is highly prevalent in fetuses with abnormalities of the great arteries (approximately 12\%). This information is important when counselling couples to undergo prenatal testing for 22q11.2DS, since this information is vital in the patients' decision of termination or continuation of pregnancy and in a well-prepared management of the affected child.

Keywords: 22q11.2 deletion syndrome; Congenital heart defect; DiGeorge syndrome; Right aortic arch; Thymus

\section{Introduction}

$22 q 11.2$ deletion syndrome (22q11.2DS) is one of the most common deletion syndromes in humans with a prevalence of 1 in 2,000 to 6,000 live births [1]. It is caused by a developmental defect of the third and the fourth pharyngeal pouches and the fourth aortic arch. This leads to several presentations, including craniofacial anomalies such as cleft palate, micrognathia, eye anomalies, congenital heart defect, absent or a small thymus, and the parathyroid gland leading to hypocalcemia and immunodeficiency, musculoskeletal
Received: 2019.12.13. Revised: 2020.01.11. Accepted: 2020.01.30. Corresponding author: Kuntharee Traisrisilp, MD Department of Obstetrics and Gynecology, Faculty of Medicine, Chiang Mai University, Chiang Mai 50200, Thailand

E-mail: kuntharee.t@cmu.ac.th

https://orcid.org/0000-0002-0980-2128

Articles published in Obstet Gynecol Sci are open-access, distributed under the terms of the Creative Commons Attribution Non-Commercial License (http://creativecommons. org/licenses/by-nc/3.0/) which permits unrestricted non-commercial use, distribution, and reproduction in any medium, provided the original work is properly cited.

Copyright $\odot 2020$ Korean Society of Obstetrics and Gynecology 


\section{Obstetrics \& Gynecology Science}

Kuntharee Traisrisilp, et al. Prenatal screening of 22q11.2DS

anomalies, developmental delay, seizure, and behavioral or psychiatric complications. Most cases (83.3-95\%) that are diagnosed prenatally are noticed by an abnormal fetal cardiac structure [2-4]. Other prenatal findings that are rarely reported, include renal anomalies, cerebral anomalies, and neural tube defects $[3,5]$. At Maharaj Nakorn Chiang Mai Hospital, the prevalence of the disease is unknown because FISH analysis for this disease is not a standard practice. In cases at this hospital, after evaluation of the fetuses by a maternal-fetal specialist, prognosis, and genetic counselling, most parents choose termination of pregnancy without further investigation (karyotyping, FISH, or microarray) due to economic limitations.

Though prenatal diagnosis of 22q11.2DS has been reported several times, most cases have been reported by western countries and are rarely from other parts of the world. Little is known about the extent of this problem in our country or in Southeast Asia. Only a few reports of 22q11.2DS among the Thai population have been studied [6-9]. Noteworthy, Wichajam and Kampan [6] reported that there was a difference in clinical phenotypes and immunological features of 22q11.2DS in north-eastern Thai children compared to those in the western countries. Moreover, to the best of our knowledge, prenatal diagnosis of 22q11.2DS has rarely been described among the Asian population. However, one retrospective study of the Korean population was reported by Lee et al. [10], who demonstrated a strong association between a variety of prenatally-diagnosed conotruncal cardiac defects and 22q11.2DS. Accordingly, prenatal diagnosis of 22q11.2DS in other parts of the world including our country remains to be explored. Thus, we conducted this prospective study with an aim to describe the experience of prenatal diagnosis of 22q11.2DS in the Thai population and to determine its prevalence among fetuses prenatally diagnosed with abnormalities of the great arteries.

\section{Materials and methods}

A prospective descriptive study was conducted the Maharaj Nakorn Chiang Mai Hospital between July 2015 and April 2018, with an ethical approval by the Institute Review Boards (Study code: OBG-2560-04711). The pregnant women meeting the inclusion criteria were invited to participate in the study with a written informed consent. The inclusion criteria were as follows: 1) women with fetuses prenatally diagnosed with abnormalities of the great arteries including conotruncal heart defects (TOF, tetralogy of Fallot; DORV, doubleoutlet of the right ventricle; TGA, transposition of the great arteries, the truncus arteriosus), aortic or pulmonary stenosis, coarctation or interrupted aortic arch, and right-sided aortic arch. 2) women undergoing fetal echocardiography in the second trimester, in which extra-cardiac anomalies and fetal thymus were included. The recruited cases were investigated for 22q11.2 deletion by in situ hybridization with a probe specific to the DiGeorgeNCFS TUPLE 1 region located on chromosome 22 for the locus D22S75 and 22qter for a telomere specific sequence clone as the control region using amniocentesis, cordocentesis, or postnatal peripheral blood. Demographic data of the pregnancies, prenatal ultrasound characteristics, and pregnancy outcomes were described and recorded in the study record form. All the recruited cases were followed until delivery for the final outcomes of pregnancy. In statistical analysis, descriptive statistics were used to express mean, standard deviation, and percentage, using SPSS version 21.0 (IBM Corp.; IBM SPSS Statistics for Windows, Armonk, NY, USA).

Table 1. Main indications for 22q11.2DS testing

\begin{tabular}{lc}
\hline Main indications & Frequency \\
\hline Right-sided or double aortic arch & $8(19.0)$ \\
Aortic stenosis or hypoplasia & $5(11.9)$ \\
TOF (simple) & $5(11.9)$ \\
TOF (complex) ${ }^{\text {a) }}$ & $5(11.9)$ \\
Pulmonary stenosis or atresia & $4(9.5)$ \\
Coarctation or interrupted aortic arch & $4(9.5)$ \\
Double-outlet right ventricle & $4(9.5)$ \\
Transposition of great arteries & $3(7.1)$ \\
Complex conotruncal defects ${ }^{\text {b) }}$ & $2(4.8)$ \\
Truncus arteriosus & $1(2.4)$ \\
Thymus hypoplasia and overriding aorta & $1(2.4)$ \\
Total & $42(100)$
\end{tabular}

Data are presented as number of frequency (\%).

TOF, tetralogy of Fallot.

a) TOF with pulmonary atresia or absent pulmonary valve or rightsided aortic arch or associated extracardiac anomalies or thymus

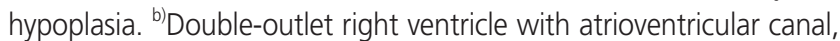
coarctation and aortic stenosis (1 case) and a case of aortic stenosis with atrioventricular canal and aberrant right subclavian artery (1 case). 


\title{
Obstetrics \& Gynecology Science
}

\author{
Vol. 63, No. 3, 2020
}

\section{Results}

During the study period from July 2015 to April 2018, 240 cases of the conotruncal cardiac anomalies were prenatally diagnosed in our institute. A total of 45 cases was tested for 22q11.2DS during the study period, with 21 cases by cordocentesis ( $22.1 \pm 3.5$ weeks of gestation), 8 cases by amniocentesis ( $16.5 \pm 1.8$ weeks of gestation), and 16 by a postnatal work-up. However, 3 cases failed to report due to a laboratory technical error. Although a large number of fetuses with cardiac abnormalities underwent fetal echocardiography at our institution, only 45 cases were tested for 22q11.2DS, because in most couples, women with fetuses with cardiac defects opted for a termination of the pregnancy after a detailed anatomical scan without further investigation. Thus, the remaining 42 , including 11 cases $(26.2 \%)$ with associated anomalies and 31 cases $(73.8 \%)$ of isolated cardiac defects were available for analysis. The mean ( \pm standard deviation [SD]) maternal age was 29.4 $\pm 7.1(17-43)$ years. The mean
$( \pm$ SD) gestational age at the time of first fetal echocardiography was $21.7 \pm 4.0(14-28)$ weeks. Various indications for 22q11.2DS testing have been presented in Table 1. Of them, either the TOF with isolated cardiac defects or the TOF with associated anomalies; i.e., pulmonary atresia, absent pulmonary valve, right-sided aortic arch, and so on, was the most common indication, accounting for approximately $24 \%$, whereas a right-sided aortic arch was the most common indication as an isolated abnormality (19\%). The prevalence of 22 q11.2DS in this series was relatively high, $11.9 \%$ (5 out of 42) among fetuses with prenatally diagnosed conotruncal heart defects. The remaining 37 cases were negative for $22 q 11.2$ deletion. In our study, termination of pregnancy because of severe fetal anomalies, mainly associated with cardiac defects, was performed in 33.3\% (14 out of 42) of the cases. Five of our 22q11.2DS cases had prenatal features and pregnancy outcomes as presented in Table 2 . The main prenatal features were conotrucal defect, mainly TOF, DORV, and right-sided aortic arch. Notably, Case 1 exhibited isolated

Table 2. Prenatal ultrasound findings and pregnancy outcomes of the cases with 22q11.2DS

\begin{tabular}{|c|c|c|c|c|c|}
\hline $\begin{array}{r}\text { Case } \\
\text { No. }\end{array}$ & $\begin{array}{l}\text { GA at } \\
\text { diagnosis } \\
\text { (wk) }\end{array}$ & $\begin{array}{c}\text { Cardiac } \\
\text { abnormality }\end{array}$ & $\begin{array}{l}\text { Other structural } \\
\text { abnormality }\end{array}$ & $\begin{array}{l}\text { Karyo- } \\
\text { type }\end{array}$ & Outcomes \\
\hline 1 & 20 & $\begin{array}{l}\text { Right-sided aortic } \\
\text { arch and ductal } \\
\text { arch }\end{array}$ & $\begin{array}{l}\text { Polyhydramnios at } 31 \text { weeks } \\
\text { (AFI } 32 \mathrm{~cm} \text {.), normal size } \\
\text { thymus }\end{array}$ & $46, X X$ & $\begin{array}{l}\text { Cesarean delivery at } 38.2 \text { wk; Surviving baby 3,075 g. } \\
\text { Apgar scores } 10 \text { at } 5 \text { min, right-sided aortic arch, } \\
\text { low-set ears, small palpebral fissure both eyes, } \\
\text { symptomatic hypocalcemia, hypothyroid, vitamin D } \\
\text { deficiency }\end{array}$ \\
\hline 2 & 20.2 & $\begin{array}{l}\text { TOF with absent } \\
\text { pulmonary valve } \\
\text { and subaortic } \\
\text { VSD }\end{array}$ & $\begin{array}{l}\text { Thymus hypoplasia }(<5 \text { th } \\
\text { percentile), bilateral } \\
\text { paramedian cleft lip and } \\
\text { palate, single umbilical } \\
\text { artery, minimal ascites }\end{array}$ & $46, X Y$ & $\begin{array}{l}\text { TOP; Hypertelorism, bilateral paramedian cleft lip, } \\
\text { low-set ears, cardiomegaly with right ventricular } \\
\text { hypertrophy, VSD perimembranous type, absent } \\
\text { pulmonary valve, absent ductus arteriosus, absence } \\
\text { thymus, mild dilation of both ureters }\end{array}$ \\
\hline 3 & 19.5 & $\begin{array}{l}\text { DORV, pulmonary } \\
\text { stenosis, ARSA, } \\
\text { perimembranous } \\
\text { VSD }\end{array}$ & $\begin{array}{l}\text { Absent thymus, bilateral } \\
\text { ventriculomegaly, abnormal } \\
\text { posture of all extremities, } \\
\text { FGR, oligohydramnios }\end{array}$ & No result & $\begin{array}{l}\text { TOP; DORV, severe PS, subaortic VSD, absent ductus } \\
\text { arteriosus, ARSA, partial syndactyly at proximal 3rd- } \\
\text { 4th digit of left hand, brachydactyly right hand, } \\
\text { rocker bottom feet }\end{array}$ \\
\hline 4 & 23.1 & $\begin{array}{l}\text { DORV (TOF-like) } \\
\text { with pulmonary } \\
\text { stenosis, VSD }\end{array}$ & $\begin{array}{l}\text { Single umbilical artery, } \\
\text { postaxial polydactyly }\end{array}$ & $46, X Y$ & $\begin{array}{l}\text { Normal delivery at } 38 \text { wk, surviving baby 2,940 g. } \\
\text { Apgar scores } 8 \text { at } 5 \text { min, normal thymus, mild } \\
\text { hypocalcemia, postaxial polydactyly, DORV with } \\
\text { staged surgical correction with fair outcome }\end{array}$ \\
\hline 5 & 18.1 & $\begin{array}{l}\text { TOF with right- } \\
\text { sided aortic arch } \\
\text { \& ductal arch }\end{array}$ & $\begin{array}{l}\text { Duodenal atresia, thymus } \\
\text { hypoplasia ( }<5 \text { th } \\
\text { percentile), polyhydramnios }\end{array}$ & $46, X X$ & $\begin{array}{l}\text { Cesarean delivery, at } 30 \text { wk, surviving baby 1,850 g. } \\
\text { Apgar scores } 9 \text { at } 5 \text { min, TOF with right-sided } \\
\text { arches, thymus hypoplasia, duodenal atresia, fair } \\
\text { outcome after surgical correction, failure to thrive, } \\
\text { neonatal death at } 1 \text { mon }\end{array}$ \\
\hline
\end{tabular}

GA, gestational age; AFI, amniotic fluid index; TOF, tetralogy of Fallot; VSD, interventricular septal defect; TOP, termination of pregnancy; DORV, double-outlet right ventricle; ARSA, aberrant right subclavian artery; FGR, fetal growth restriction; PS, pulmonary stenosis. 


\section{Obstetrics \& Gynecology Science}

Kuntharee Traisrisilp, et al. Prenatal screening of 22q11.2DS

right-sided arches only without any other conotruncal or cardiac anomalies, whereas 2 cases underwent a termination of pregnancy and one experienced preterm birth with death of the neonate. Two cases survived with a prolonged NICU admission. Fig. 1 demonstrates examples of prenatal ultrasound findings and pathological findings post the termination of pregnancy in cases of 22q11.2DS. Additionally, fetal karyotyping was performed in 26 cases, resulting in $46, X X$ (11 cases); 46,XY (10 cases); 47, XX, +18 (1 case); 47,XY, +13 (1 case); 47,XY, 21 (1 case); 46XX,r(13) (1 case) and 69,XXY (1 case).

\section{Discussion}

Insights gained from this study demonstrate that among the Thai or probably the Asian population, the prevalence of 22 q $11.2 \mathrm{DS}$ is as high as nearly $12 \%$ of the fetuses prenatally diagnosed with abnormalities of the great arteries. It may be concluded that the prevalence is similar to that reported in western countries. Our evidence strongly suggests that pregnancies with a prenatal detection of abnormal great arteries should be encouraged to test for fetal 22q11.2DS. Owing to the fact that prenatal screening of 22q11.2DS has never been practiced in our country, our finding can probably lead to a change in our practice in Thailand and Southeast Asia, although analysis of its cost-effectiveness remains to be explored.

22q11.2DS has been documented far more in newborns than those in fetuses. The clue to a prenatal diagnosis is the presence of a congenital heart disease. The large prenatal series found that conotruncal heart defects were the most common fetal phenotype (92\%) followed by a thymic hy- poplasia (86\%) and a urinary tract abnormality (34\%) [3]. Conotruncal malformations refer to the abnormality involving either the aortic or the pulmonary outflow tract, and is more relevant than the non-conotruncal malformations $[2,11]$. The most prevalent cardiac defect in literature is the TOF, accounting for $20-45 \%$, followed by pulmonary atresia with VSD; $10-25 \%$ [12]. In our study, 4 out of the 5 cases were categorized as cases with a conotruncal defect and one case exhibited only a right-sided aortic arch. The specific cardiac defect is the main cause of neonatal death, at an average age of 3-4 months [13]. Also in adults, sudden cardiac death and heart failure are the most common causes of death, even in patients without a congenital heart disease [14].

Notably, in this study, the isolated right-sided aortic arch without other structural anomalies was found in 1 of the 5 cases with 22q11.2DS, consistent with the findings reported in western countries [15]. However, an abnormal laterality associated with 22q11.2DS may include a right-sided aortic arch, double aortic arch, cervical aortic arch, and an abnormal origin of the subclavian arteries [13]. A recent meta-analysis showed that the proportion of 22q11.2 deletion was 5.1 $(95 \% \mathrm{Cl}, 2.4-8.6)$ in fetuses with a right-sided aortic arch and in the absence of other intra-cardiac or extra-cardiac abnormalities [15]. However, 5\% of these had extra-cardiac abnormalities detected after birth such as a unilateral renal agenesis and a gastrointestinal malformation [15]. Thus, in cases of isolated abnormalities of the aortic arch, a follow-up study and an immediate postnatal echocardiography and an electrolyte study to detect other associated anomalies that may be overlooked in the first scan are highly recommended $[1,16]$. Early detection and management can improve fetal and neonatal outcomes.

When Case 1 was diagnosed with 22q11.2DS at 20 weeks
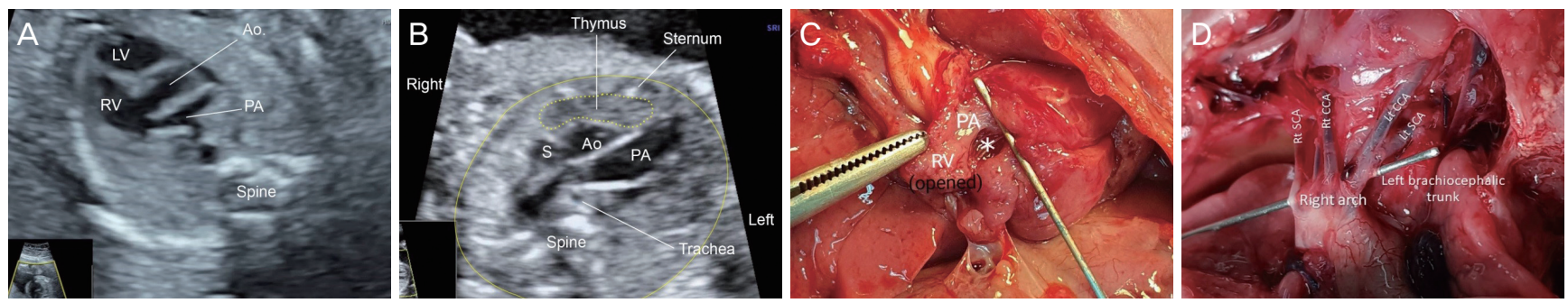

Fig. 1. Examples of the findings of fetuses with 22q11.2DS: prenatal ultrasound findings of double-outlet right ventricle (A: Case 4), and right-sided aortic arch with relatively small thymus (B: Case 5); and pathological findings of absent pulmonary valve (C: Case 3) and rightsided aortic arch (D: Case 5). Asterisk (*) presented pulmonary annulus. LV, left ventricle; RV, right ventricle; Ao, aorta; PA, pulmonary artery; S, superior vena cava; SCA, subclavian artery; CCA, common carotid. 


\title{
Obstetrics \& Gynecology Science
}

\author{
Vol. 63, No. 3, 2020
}

of gestation, the couple decided to continue pregnancy after comprehensive counselling. During prenatal follow-up, polyhydramnios developed at 31 weeks of gestation (amniotic fluid index [AFI], $32 \mathrm{~cm}$ ) and amnioreduction was performed 1 week later due to maternal discomfort (AFI, $39 \mathrm{~cm})$. The cause of polyhydramnios was unclear. Hypothetically, it was due to an airway compression by the right-sided aortic arch. However, it may be also caused by an airway abnormality $[17,18]$, but the cause of the polyhydramnios in our case was not proved postnatally. Sacca et al. [19] reported that about $70 \%$ of the patients with a $22 q 11.2$ deletion syndrome were identified to have airway anomalies including tracheomalacia (36\%), subglottic stenosis (28\%), and laryngomalacia (26\%). Thus, the evaluation of airway structure and function should be considered and included in a systemic assessment among these patients since it can sometimes lead to a neonatal death.

Our series also supported that absent or hypoplastic thymus (in 3 out of 5 cases), is an indication for determination of 22q11.2DS. Chaoui et al. [20] suggested that the thymusthoracic ratio of less than 0.25 was highly correlated with 22q11.2DS. Thymus size can be evaluated by measurement of the thymus diameter or thymus-thoracic ratio and comparison with reference ranges. We encourage the use of thymus diameter because our previous study showed that thymus diameter was more reproducible and simpler than the thymus-thoracic ratio [21].

Extracardiac abnormalities associated with 22q11.2DS include CNS anomalies (15.4-38\%) [3,4], polyhydramnios (9.2-30\%) [2,4], facial dysmorphism (5.9-21\%) [2,4], skeletal defects (16.9-19\%) [3,4], genitourinary disorders (10-33.8\%) [3,4,22], gastrointestinal anomalies (14\%) [4], and pulmonary disorders (7\%) [4]. More than $90 \%$ of these anomalies were not isolated [2]. In our series, only 1 case exhibited an isolated cardiac defect, whereas the others had associated anomalies. Association between FGR and 22q11.2DS has been inconsistently reported, from no association [4], to strong association [2]. Furthermore, 7.4-15\% of the fetuses show increased nuchal translucency in the first trimester $[2,3]$.

In the general population, due to multiple and non-specific prenatal presentations, it may be difficult to set the guideline for 22q11.2 analysis. Prompt investigation for 22q11.2DS when congenital heart disease is diagnosed by fetal echocardiography is widely accepted especially defects with a very high risk such as an interrupted aortic arch, type B (50-80\% risk), truncus arteriosus (30-50\%), pulmonary atresia with VSD with MAPCAs (30-45\%) [23-26]. Based on emerging knowledge, prenatal 22q11.2 analysis is also recommended when ultrasounds show other congenital heart defects combined with other structural abnormalities (as mentioned above), and increased NT in the first trimester $[2,4]$. This study suggested that, among the Thai and probably the Asian populations, when abnormalities of the great arteries and/or thymus hypoplasia are detected on fetal echocardiography, 22q11.2DS should be taken into account for differential diagnoses and should be selectively tested. Though such a work-up is expensive in our country, the prevalence of the disease is relatively high in cases of the great artery abnormalities and testing in such cases may be worthwhile. The strengths of this study were: 1) A prospective nature of the study enabled us to determine the prevalence of 22q11.2DS among fetuses with conotruncal anomalies. 2) Pediatric echocardiography or fetal autopsy was performed to confirm prenatal ultrasound findings. The weaknesses of this study that could limit its generalizability were: 1) The sample size was too small to allow us to make conclusions with high confidence. 2) Only Thai pregnancies were recruited. Therefore, the study population could not perfectly represent other populations even in Asia.

In conclusion, in an era of a high resolution of ultrasonography, many regions have standard guidelines for prenatal anatomical screening, leading to an increasing number of prenatal diagnoses of 22q11.2DS. The main finding of the disease is the presence of abnormal great arteries and thymus hypoplasia, but it can also be associated with a variety of other anomalies. Similar to the reports in the western countries, we have documented that among Thai pregnant women, 22q11.2DS is highly prevalent in fetuses with abnormalities of the great arteries (approximately 12\%). This information is important when counseling couples to undergo a prenatal test for 22q11.2DS, since this information is helpful in patients' decisions of termination or continuation of pregnancy, or in a well-prepared management of the affected child.

\section{Acknowledgements}

This research was financially supported by the Chiang Mai University Research Fund (CMU-2562). 


\section{Obstetrics \& Gynecology Science}

Kuntharee Traisrisilp, et al. Prenatal screening of 22q11.2DS

\section{Conflicts of interest}

No potential conflict of interest relevant to this article was reported.

\section{Ethical approval}

Ethics approval for this study was granted by the Institute Review Boards, Faculty of Medicine, Chiang Mai University, Thailand (Study code: OBG-2560-04711).

\section{Patient consent}

The patients provided written informed consent for the publication and the use of their images.

\section{References}

1. Bassett AS, McDonald-McGinn DM, Devriendt K, Digilio MC, Goldenberg P, Habel A, et al. Practical guidelines for managing patients with 22q11.2 deletion syndrome. J Pediatr 2011;159:332-339.e1.

2. Besseau-Ayasse J, Violle-Poirsier C, Bazin A, Gruchy N, Moncla A, Girard F, et al. A French collaborative survey of 272 fetuses with 22q11.2 deletion: ultrasound findings, fetal autopsies and pregnancy outcomes. Prenat Diagn 2014;34:424-30.

3. Noël AC, Pelluard F, Delezoide AL, Devisme $L$, Loeuillet $L$, Leroy $B$, et al. Fetal phenotype associated with the 22q11 deletion. Am J Med Genet A 2014;164A:2724-31.

4. Schindewolf $E$, Khalek N, Johnson MP, Gebb J, Coleman $B$, Crowley TB, et al. Expanding the fetal phenotype: Prenatal sonographic findings and perinatal outcomes in a cohort of patients with a confirmed 22q11.2 deletion syndrome. Am J Med Genet A 2018;176:1735-41.

5. Nickel RE, Magenis RE. Neural tube defects and deletions of 22q11. Am J Med Genet 1996;66:25-7.

6. Wichajam K, Kampan J. Difference of clinical phenotypes and immunological features of 22q11.2 deletion syndrome in north-eastern Thai children compare to western countries. J Med Assoc Thai 2014;97 Suppl 10:S59-66.
7. Ruangdaraganon N, Tocharoentanaphol C, Khowsathit P, Sombuntham T, Pongpanich B. Chromosome 22q11 deletion syndrome: the first three cases reported in Thailand. J Med Assoc Thai 1999;82 Suppl 1:S179-85.

8. Kruszka P, Addissie YA, McGinn DE, Porras AR, Biggs E, Share $M$, et al. 22q11.2 deletion syndrome in diverse populations. Am J Med Genet A 2017;173:879-88.

9. Korpaisarn S, Trachoo O, Sriphrapradang C. Chromosome 22q11.2 deletion syndrome presenting as adult onset hypoparathyroidism: clues to diagnosis from dysmorphic facial features. Case Rep Endocrinol 2013;2013:802793.

10. Lee MY, Won HS, Baek JW, Cho JH, Shim JY, Lee PR, et al. Variety of prenatally diagnosed congenital heart disease in 22q11.2 deletion syndrome. Obstet Gynecol Sci 2014;57:11-6.

11. Kong CW, Cheng YK, To WW, Leung TY. Prevalence of chromosomal abnormalities and 22q11.2 deletion in conotruncal and non-conotruncal antenatally diagnosed congenital heart diseases in a Chinese population. Hong Kong Med J 2019;25:6-12.

12. Momma K. Cardiovascular anomalies associated with chromosome 22q11.2 deletion syndrome. Am J Cardiol 2010;105:1617-24.

13. Unolt M, Versacci P, Anaclerio S, Lambiase C, Calcagni G, Trezzi $\mathrm{M}$, et al. Congenital heart diseases and cardiovascular abnormalities in 22q11.2 deletion syndrome: From well-established knowledge to new frontiers. Am J Med Genet A 2018;176:2087-98.

14. Bassett AS, Chow EW, Husted J, Hodgkinson KA, Oechslin $E$, Harris $L$, et al. Premature death in adults with 22q11.2 deletion syndrome. J Med Genet 2009;46:32430.

15. McElhinney DB, Clark BJ 3rd, Weinberg PM, Kenton ML, McDonald-McGinn D, Driscoll DA, et al. Association of chromosome 22q11 deletion with isolated anomalies of aortic arch laterality and branching. J Am Coll Cardiol 2001;37:2114-9.

16. Fung WL, Butcher NJ, Costain G, Andrade DM, Boot E, Chow EW, et al. Practical guidelines for managing adults with 22q11.2 deletion syndrome. Genet Med 2015; 17:599-609.

17. Fokstuen S, Bottani A, Medeiros PF, Antonarakis SE, Stoll C, Schinzel A. Laryngeal atresia type III (glottic web) with 22q11.2 microdeletion: report of three patients. Am J 


\section{Obstetrics \& Gynecology Science}

Vol. 63, No. 3, 2020

Med Genet 1997;70:130-3.

18. Leopold C, De Barros A, Cellier C, Drouin-Garraud V, Dehesdin D, Marie JP. Laryngeal abnormalities are frequent in the 22q11 deletion syndrome. Int J Pediatr Otorhinolaryngol 2012;76:36-40.

19. Sacca R, Zur KB, Crowley TB, Zackai EH, Valverde KD, McDonald-McGinn DM. Association of airway abnormalities with 22q11.2 deletion syndrome. Int J Pediatr Otorhinolaryngol 2017;96:11-4.

20. Chaoui R, Heling KS, Lopez AS, Thiel G, Karl K. The thymic-thoracic ratio in fetal heart defects: a simple way to identify fetuses at high risk for microdeletion 22q11. Ultrasound Obstet Gynecol 2011;37:397-403.

21. Pittyanont S, Luewan S, Tongsong T. Cardio-STIC based reference ranges of fetal thymus size in singleton pregnancies. J Ultrasound Med 2017;36:1181-8.

22. Burtey S. 22q11.2 microdeletion syndrome is a common cause of renal tract malformations. Nat Clin Pract Nephrol 2008;4:E1.
23. Digilio MC, Marino B, Grazioli S, Agostino D, Giannotti A, Dallapiccola B. Comparison of occurrence of genetic syndromes in ventricular septal defect with pulmonic stenosis (classic tetralogy of Fallot) versus ventricular septal defect with pulmonic atresia. Am J Cardiol 1996;77:1375-6.

24. Goldmuntz E, Clark BJ, Mitchell LE, Jawad AF, Cuneo $B F$, Reed $L$, et al. Frequency of $22 q 11$ deletions in patients with conotruncal defects. J Am Coll Cardiol 1998;32:492-8.

25. Marino B, Digilio MC, Toscano A, Anaclerio S, Giannotti $A$, Feltri $C$, et al. Anatomic patterns of conotruncal defects associated with deletion 22q11. Genet Med 2001;3:45-8.

26. Peyvandi S, Lupo PJ, Garbarini J, Woyciechowski S, Edman S, Emanuel BS, et al. 22q11.2 deletions in patients with conotruncal defects: data from 1,610 consecutive cases. Pediatr Cardiol 2013;34:1687-94. 